\title{
EL ABASTECIMIENTO Y VENTA DE CARNES EN ORIHUELA DURANTE EL REINADO DE ALFONSO V (1416-1456)
}

\author{
Juan Antonio BARRIO BARRIO \\ Universidad de Alicante
}

En el siglo XV los miembros del consistorio oriolano intervenían en asuntos de índole política, administrativa, servicios sociales, enseñanza, obras públicas, etc., y en sus deliberaciones aprobaban resoluciones que afectaban a la economía local. Es la intervención plena de la universitas sobre los sectores productivos del término(1).

\section{EL ABASTECIMIENTO.}

Una de las principales preocupaciones de las autoridades locales era el abastecimiento de productos básicos como cereales, carne y pescado.

En Orihuela la venta de los principales productos de consumo se desarrollaba en el mercado, que desde el siglo XIII se celebraba los miércoles de cada semana, donde se vendían productos como los cereales y el vino común, mientras que el pan y la carne se expendían en establecimientos fijos, previa concesión de su gestión por parte del consistorio a determinadas personas.

El adecuado abastecimiento y venta de carnes quedó regulado en 1321, con un privilegio de Jaime II que autorizaba la instalación de ocho tablas en la plaza del mercado, junto al puente, prohibiendo la proliferación arbitraria de los puestos de venta, ya que suponía un grave peligro para la salud pública. Se establecía sobre las mismas un censo o impues- 
to anual de cuatro maravedís de oro a pagar la fiesta de Navidad. El municipio podía vender, alienar, permutar, etc. las carnicerías, excepto a miembros del clero y satisfaciendo los pertinentes derechos de laudemio y fadi$\mathrm{ga}^{(2)}$.

El consell cedia anualmente su gestión a particulares, a cambio de tenerlas abastecidas en el periodo establecido, fijando el precio de la libra de carne y el pago de la sisa pertinente(3). Los jurados gestionaban esta cesión atendiendo las ofertas más interesantes, en función del precio de la carne y el volumen de ganado que se comprometían a sacrificar los futuros arrendatarios. El consell aprobaba finalmente los capitulos acordados entre los jurados y los futuros gestores de las carnicerías ${ }^{(4)}$. El interés teórico del consistorio era velar por el bien público y asegurar unos mínimos niveles anuales en el consumo de carne, pero también primaban las necesidades fiscales, ya que las arcas municipales se nutrían principalmente con la cesión del cobro de la sisa, impuesto indirecto que gravaba el consumo de productos como la carne(5). Como en otras localidades la cesión anual de tablas variaba en función de la oferta, que determinaba las condiciones pactadas entre los jurados y los arrendatarios(6). Los aseguradores o arrendatarios disfrutaban de la ventaja de poder pastar el ganado en los bovalares o dehesas carniceras, que eran las zonas reguladas por el consistorio para las reses que se destinaban al abasto de carnes de la villa(7).

Otro de los problemas habituales de los municipios era el control del abastecimiento(8). El principal objetivo, como quedaba fijado en los capítulos de la cesión de las carnicerías, era asegurar la venta diaria de carne fresca. Para ello en ocasiones se vedaba, mediante pregón público, la salida de ganado y su venta salvo que fuese para provisión del término. La prohibición solía afectar a carneros, corderos, borregos, ovejas, machos cabríos, cabras, cerdos, cerdas, vacas y bueyes(9). En el siglo XV el carnero (moltó) se convirtió en el principal producto de consumo cárnico. En segundo lugar se encontraban las denominadas carnes menudas: cabrón, cordero, oveja, cerdo, etc(10).

El consistorio, al igual que con el trigo, cuando lo consideraba oportuno ordenaba el inventariado del ganado que había en la huerta, para el aprovisionamiento de la urbe. En 1433 ordenó censar los carneros y cabrónes para tal fin y mediante bando público comunicaba, que quienes tuviesen ganado y quisiesen vender carne, no pudiesen tener carnicería de oveja sino tenían otra de carnero. También se prohibía pastar ovejas, sino se tenía igual número de carneros; al tiempo que prohibía a aquellos ganaderos que contasen con más ovejas que carneros llevar a pastar a las primeras, hasta que las hubiese manifestado a los jurados en presencia del escribano municipal. Asímismo estipulaba que se podía matar y vender carne de cordero, aunque 
no se tuviese ninguna mesa de carnero. La consecuencia de todo ello es que en 1433 la carne que más abundaba era la de oveja en detrimento de la de carnero(11).

La intervención municipal sobre el abastecimiento se centraba en asegurar un volumen adecuado diario de carne, en cantidad y calidad, en las mesas que estaban ubicadas en la villa, con un claro predominio del carnero.

\section{CONTROL DE LA OFERTA.}

También junto al habitual arrendamiento o cesión de las carnicerías a aseguradores, el consistorio aprobaba con cierta periodicidad medidas encaminadas a asegurar la oferta de carne y la variedad de la misma(12). Con la subida del precio se pretendía incrementar la oferta de determinada carne. En 1433 aprobó una ordenanza subiendo a diez dineros la libra, el precio del cabrón y del cerdo que entrase en la villa a partir del ocho de septiembre de dicho año. Para las reses inventariadas se mantenía al precio anterior de 9 dineros. La medida fue adoptada ya que al precio de 9 dineros la libra de carne, con 3 dineros de sisa, había carestía del producto por el bajo precio que no estimulaba la oferta(13).

Junto a ello el municipio facilitaba la entrada y venta libre de carnes, a un precio menor que el pactado con los aseguradores, ofreciendo a los interesados la tabla municipal. Estas medidas liberalizadoras chocaban con los intereses de los arrendatarios, que impedían el acceso al consumidor de esta carne más barata comprando las reses que se iban a ofertar, para mantener el control sobre el mercado. Por ello a partir de 1445 en los capítulos de arrendamiento se prohibía a los aseguradores comprar las reses que iban a ser sacrificadas en dicha tabla. Ello era posible porque los aseguradores eran ganaderos con capacidad empresarial para reunir de 1500 a 3000 cabezas de carnero, ofertar a las autoridades locales la venta de dicha carne y controlar así el mercado cárnico local. Con ello se complementaban los intereses públicos del municipio: fiscales, cobro de la sisa, y sociales, asegurar el abasto, con los privados: lograr el control de la venta y distribución interna de un producto básico de consumo en el siglo XV como era la carne(14).

Las autoridades locales también se preocupaban por la calidad de las carnes vendidas, ante las quejas que presentaban los interesados en el tema, los arrendatarios de la sisa, preocupados por el buen abastecimiento del término en cantidad y calidad, ya que tenían que rentabilizar la inversión realizada. La falta de provisión de carnes y la queja de que se mataba ganado de mala calidad perjudicaba a los consumidores y a los siseros por la disminución en la venta del producto(15). 


\section{LOS PRECIOS.}

Uno de los principales problemas que afrontaba el municipio era la regulación de los precios de los productos principales de consumo(16). En uno de los capítulos del arrendamiento de las carnicerías, se fijaba el valor y el gravamen correspondiente, por libra de carne.

En ocasiones el consell aprobaba la tarifa que los jurados habían pactado con los carniceros o aseguradores, que se fijaba según la fecha del año. Así en marzo de 1416 se estableció un importe desde dicho mes hasta el 29 de septiembre (San Miguel), y otro desde esta última fecha hasta la fiesta de carnavales. El consistorio tenía facultad para reservarse una carnicería para vender la carne a un dinero menos que los arrendatarios(17).

\section{PRECIOS FIJADOS POR EL CONSELL PARA LA CARNE. S. XV.}

(Valor expresado en dineros por libra de carne. El valor correspondiente que se detrae para la sisa entre paréntesis )

$\begin{array}{lrr}\text { AÑo 1416. } & \text { Marzo-Junio } & \text { Junio-Carnav. } \\ \text { Producto } & \text { Valor } & \text { Valor } \\ \text { Carnero } & 10(3) & 11(3) \\ \text { Cordero } & 9(3) & 9(3) \\ \text { Cabrón } & 9(3) & 9(3) \\ \text { Oveja } & 8(2) & 8(2) \\ \text { Buey } & 8(2) & 8(2) \\ & & \\ \text { AÑo 1417. } & \text { Marzo-Junio } & \text { Junio-Carnav. } \\ \text { Carnero } & 10(3) & 11(3) \\ \text { Cordero } & 9(3) & 9(3) \\ \text { Cabrón } & 9(3) & 10(3) \\ \text { Buey, vaca y salvajinas. } & 8(2) & 8(2) \\ \text { Cerdo } & 10(3) & 10(3) \\ \text { Cerda sanada } & 8(2) & 8(2)\end{array}$

\section{AÑo 1418}

Carnero.

Cordero.

Oveja.

Buey, vacas y salvajinas.

Cerdo y cerda sanada.

Cerda sin sanar.

Bueyes de labradores(18). 
AÑo 1418

Cabrón.

AÑO 1421

Carnero

Cordero

Cabrón

Cerdo

Oveja

Buey y vaca

Salvajina

\section{AÑO 1432}

Carnero

Cordero

Cabrón

Cerdo

Oveja

Cabra

Buey y vaca

Salvajina

AÑO 1440.

Carnero

Cabrón

Oveja y cabra

Cerdo

Salvajina

Bou y vaca

AÑO 1443

Carnero

Cabrón

Oveja

AÑo 1445

Carnero

Cabrón

Cordero

Oveja
Pascua-San Juan. S.Juan-fin contrato.

9(3)

10(3)

Mayo-Junio (S. Juan) Junio (S.Juan)-Carnavales.

$\begin{array}{rr}12(3) & 13(3) \\ 10(3) & 10(3) \\ 10(3) & 10(3) \\ 10(3) & 10(3) \\ 8(2) & 8(2) \\ 8(2) & 8(2) \\ 8(2) & 8(2)\end{array}$

$11(3)$

9

9

9

8

7

8

8

S.Miguel-

Cuaresma. Pascua-

Carnaval

S.Miguel.

12(3)

13(3)

11(3)

7

6

8

7

6

Octubre-Pascua quincuagésima

12(3)

10(3)

8(3)

Marzo-Septiembre. Octubre-Carnest.

11(3)

12(3)

9(3)

10(3)

9(3)

9(3)

$8(3)$

$8(3)$ 
AÑo 1446.

Carnero

AÑo 1447.

Carnero

Carnero

AÑo 1451.

Carnero

Cordero (hasta San Juan).

Oveja.

Cabrón.

AÑo 1455.

Carnero

Cordero

Cabrón

Oveja

AÑO 1456.

Carnero

Cabrón

Oveja

Cordero

AÑo 1458

Carnero

Cabrón

Oveja

Cordero hasta Pascua

10(3)
Pascua-Septiemb.

11(3)
Septiembr.-Carnavales.

12(3)

Abril-Carnavales.

11(3) Primeros 1.500 carneros.

12(3) Restantes 1.500 carneros.

Abril-Agosto

11(3)

Septiembre-Carnav.

12(3)

$9(3)$

$8(3)$

$10(3)$

Pascua-Septiembre

$11(3)$

$9(3)$

$9(3)$

$8(3)$

Junio-Santa María de Agosto

11(3)

9(3)

$8(3)$

$9(3)$

Mayo-Agosto Septiembr. Carnavales

11(3)

12(3)

Mayo-Diciembre.

$9(3)$

$8(3)$

Mayo-San Juan.

$9(3)$
Septiembre-Carnavales.

12(3)

10(3)

$9(3)$

8(3)

Santa María-Carnavales

12(3)

$10(3)$

$9(3)$

10(3)

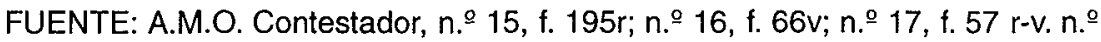

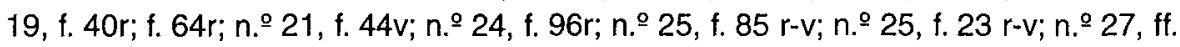

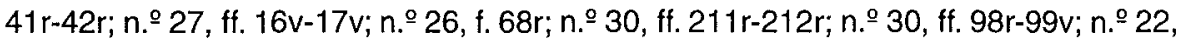
ff. $58 \mathrm{r}-59 \mathrm{v}$.

Destacar la escasa evolución del precio y gravamen de la carne en el período estudiado. 


\section{LOS PASTOS.}

Una de las preocupaciones del consell de Orihuela era asegurar el abastecimiento de carnes en el término, por lo que prohibía la salida de ganado del mismo. También concedía licencias para que pudiese entrar ganado en la huerta del término, que otorgaba siempre y cuando se destinase para el abastecimiento y consumo local(19).

Por otra parte, los carniceros tenían permiso para pastar en la huerta del término el ganado que iba ser sacrificado para el consumo(20). Como los desperfectos que causaban en las tierras de cultivo no eran penados convenientemente ante el problema de descubrir al dueño responsable, el consell decidió en 1418 dividir la huerta, para distribuir el ganado de cada carnicero en un sector diferente y así poder saber que ganado causaba los daños(21). Los esfuerzos del consistorio no solucionaban la tradicional dicotomía agricultura-ganadería, ya que los problemas siguieron reproduciéndose, pues los jurados informaron que los carniceros llevaban por la huerta más ganado del autorizado y muchas cabras, contra lo estipulado por el consell, que ordenó al justicia criminal y jurados ejecutar las penas pertinentes sobre esta cuestión y hacer salir dicho ganado de la huerta; a la vez que se reiteró la orden de partir la huerta entre los carniceros(22). El hecho de que el ganado de los carniceros pudiese pastar en la villa no quiere decir que todo la carne que se consumía en Orihuela, procedía del ganado que pastaba en el término, ya que los ganaderos oriolanos acudían a ferias para comprar reses con destino a las carnicerías municipales(23), lo que suponía un ahorro importante del espacio destinado a pastos, que podía aprovecharse mejor en la producción de cereales(24).

Como posible medida para evitar el malestar de los agricultores por el ganado que pastaba en la huerta, el "manifest de les carns qui son en la orta e terme de la vila de oriola"(25) conservado en las actas de 1432 es una muestra del control que ejercían los jurados sobre el ganado dedicado al consumo que se encontraba pastando en la huerta.

El resultado del manifiesto es el siguiente:

- Ferrando Martínez, 100 ovejas, 800 carneros, 100 cabras/ones.

- Lluís Soler, 300 ovejas, 100 cabras/ones.

- Gil García, 500 ovejas, 100 borregos, 600 cabras/ones.

- Ginés Tribes, vecino de Callosa, 430 cabezas entre cabrónes y carneros.

De nuevo el consell ordenó en 1432 que los ganados de las carnicerías fuesen divididos por partidas, prohibiendo a cada dueño introducir su cabaña en otra partida de la que tenía asignada(26) y promulgo la habitual 
ordenanza prohibiendo que los ganados entrasen a pastar en la huerta, por el daño que causaban(27).

En 1443 se realizo un nuevo manifiesto sobre el ganado que pastaba en la huerta, cuyo resultado es el siguiente:

- Daniel Quexans, 1400 carneros/borregos.

- Gil García, 500 carneros.

- Alvadejone, 400 carneros.

- Luis Soler, 400 carneros.

- Manuel Alvarez y Joan Martínez, 500 carneros(28).

\section{LUGARES DE VENTA Y CARNICEROS.}

La intervención municipal afectaba también a la venta y distribución interna del producto. Jaime II había establecido ocho tablas de carne, siete que arrendaba el consell y una que se podía reservar, que cedía libremente para la venta de carne a un dinero menos(29). De las tablas que arrendaba, en tres o cuatro se vendía carne de carnero, mientras que en las otras se vendían el resto de carnes: cordero, oveja, vaca, etc. Al menos hasta 1443 las tablas se encontraban en la carnicería mayor, ubicada en la plaza mayor de la ciudad, y desde esta fecha aparece una nueva ubicada en el arrabal de la puerta nueva donde se solían arrendar dos mesas(30).

El justicia criminal y los jurados de la villa, ejecutaban en nombre del consell el arrendamiento de las carnicerías.

\section{ARRENDAMIENTO DE TABLAS DE CARNE EN ORIHUELA. S. XV.}

AÑO ARRENDAMIENTO

1416

1417

1418

1421

1433

1440

1443

1445

1446
NUMERO TABLAS Y TIPO CARNE.

4 carnero 1 cabrón y 1 cordero

4 carnero y 3 resto carnes

3 carnero y 6 resto carnes

6 carnero y 6 resto carnes

3 carnero, 3 cabrón y 1 cerdo

Las carnicerías de la plaza

2 carnero, 1 carnes menudas y

en el ravalet 1 carnero

2 carnero, 2 resto carnes y

en el ravalet 1

Carnicerías de la ciudad. 
1447

1451

1455

1456

1458
Carnicerías de la ciudad.

2 carnero, 2 resto carnes y en el ravalet 1 (carnero, cabrón, oveja o cordero)

3 carnero, 2 carnes menudas y en el "raval de la porta nova" 1 carnero y 1 carnes menudas. 3 carnero, 3 carnes menudas. 2 carnero, 2 carnes menudas. "ravalet": 1 carnero

FUENTE: A.M.O. Contestador, n.ำ 16, f. $66 \mathrm{v}$. n. .917, f. 57 r-v. n. 019 , f. 64 r-v. n. 021 ,

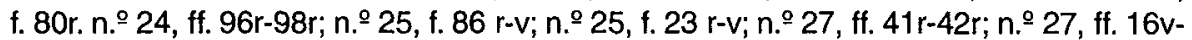
$17 v$; n. 26, ff. 68r-69r; n. 30, ff. 211r-212r; n. 930 , ff. 98r-99v; n. ${ }^{2} 22$, ff. 58r-59v.

Las referencias generales que aparecían en los capítulos de los contratos de cesión de carnicerias son las siguientes:

1. Nombre de los carniceros y tablas que arriendan, indicándose el tipo de carne. Se podía incluir la obligación de tenerlas abastecidas de sol a sol y el tipo de multa por infringirla, que solía ser de 30 sueldos, repartidos en tercias entre la corona, el consell y los arrendatarios de la sisa.

2. Tiempo de duración del contrato. Suele ser de Pascua de un año a Carnestolendas del siguiente(31).

3. Precio de venta de la carne y gravamen en concepto de sisa.

4. El consell se reserva una tabla fijándose en el contrato las condiciones de gestión de la misma.

Cada carnicero solía arrendar dos o tres mesas, una para venta de carnero y las otras para el resto de carnes. A principios del siglo XV cuatro monopolizaban dicho arrendamiento(32).

El control de la cesión lo ejercía el consell, que podía revocar una concesión realizada a un carnicero en beneficio de otro que ofreciese mejor oferta de venta ante el consistorio(33), cuyo interés era asegurar el abastecimiento de carne, por lo que mediaba en los enfrentamientos que se producían entre ellos para evitar conflictos(34). Por ello admitía las ofertas que más le convenian. Cuando en 1421 el mensajero de la villa en la ciudad de Valencia informó que había encontrado dos carniceros dispuestos a venir a Orihuela a vender carne, el justicia criminal y los jurados le comunicaron los precios a los que se había fijado la venta de carne para el año en curso, y que si las aceptaban harían mandamientos a los carniceros locales para que no vendiesen más y conseguir que los carniceros valencianos acudiesen a 
tal fin(35). Finalmente no se comprometieron y fueron dos vecinos de Orihuela y un tercero de Alcaudete, los que arrendaron dos carnicerías de carnero y otras dos con el resto de carnes, que tenían que estar abiertas de sol a sol. Durante el domingo y fiestas de guardar tenian que tener abiertas de sol a sol tres carnicerías de carnero y una con el resto de carnes. El jueves sólo tendrían una carnicería de carnero. Los tres aseguradores se comprometían desde la fecha del compromiso hasta las próximas fiestas de carnavales a tener las mencionadas carnicerías, al precio que habian acordado con el conselly jurados y bajo la correspondiente sisa o gravamen. Cualquier infracción que cometiesen estaba castigada con una multa de treinta sueldos, correspondiendo la tercera parte al sisero de la villa. Los tres aseguradores tenían autorización para llevar por la huerta del término quinientas cabezas de ganado por carniceria, de las que doscientas cincuenta debían ser ovejas. Durante el mes de agosto las cabezas de oveja que sobraran podían sacarlas fuera de la villa y huerta, al lugar fijado por las autoridades municipales. Los carniceros estaban obligados a pagar todos los daños que su ganado provocase en las tierras de cultivo, quedando exentos de intervenir en esta cuestión los arrendatarios de las caloñas de la huerta del término(36). Los jurados se comprometían a sacar de la huerta todo el ganado que hubiese en ella, excepto los corderos, que ya estaban comprometidos para las carnicerías de la villa(37). Las condiciones fijadas en el contrato de 1421, con algunas variantes, solían ser las habituales.

\section{ABASTECEDORES DE LAS CARNICERÍAS DE ORIHUELA (1416-1458)}

ANNOY FECHA ARRENDAM. ABASTEC.

$1416,04,10$.
Domingo
Salvanya
DURACIÓN.

Desde

pascua

florida a

carnestol.
BANCOS.

5

"tota la

carnicería

de la dita vila"

CONDICIONES ESPECIFICAS AÑO 1416. año.

1. Debe tener la carnicería de la villa abastecida de carnes por un tiempo de un

2. Las fiestas de Pascua, Santa María, Apóstoles, fiestas de guardar y domingos debe tener de sol a sol cuatro tablas de carnero, una de cabrón y otra con oveja y cordero.

3. El resto de días tres tablas de carnero y dos con el resto de carnes.

4. El jueves después de vísperas era suficiente con tener una de las tablas abastecidas de carnes todo el día.

5. El arrendatario podía pastar ganado en la huerta. Por cada mesa de carnero hasta 500 cabezas, sin fijarse cantidad para el resto de reses.

6 . El carnicero pagaría todo el daño que sus animales realizasen sobre los cereales, viñas y barbechos así en secano como en regadío. 
7. El consell se reservaba una tabla para bueyes, vacas y salvagines.

ANOO YECHA ARRENDAM. ABASTEC. DURACIÓN. BANCOS.

1417

(marzo, 29)
Ferrando

Martínez
Desde abril

a carnestol.
2 (una de

carnero y otra con el resto de carnes)

1417 Alfonso

Sanchez

Id.

1 (carnero)

1417

Pascual

Sanchez

Id.

2 (carnero y

resto carnes)

1417

Ferrando

Martí

Id.

Id.

CONDICIONES ESPECIFICAS ARRENDAMIENTO AÑO 1417.

Deben tener 50 cabezas por tabla en la huerta. El consell se reserva una tabla por si alguien quiere cortar carne desde San Miguel en adelante a un dinero menos.

\begin{tabular}{|c|c|c|c|}
\hline AÑO Y FECHA ARRENDAM. & ABASTEC. & DURACIÓN. & BANCOS. \\
\hline $\begin{array}{l}1418 \\
(\text { marzo, 6) }\end{array}$ & $\begin{array}{l}\text { Ferrando } \\
\text { Martínez, } \\
\text { carnicero. }\end{array}$ & $\begin{array}{l}\text { Desde } \\
\text { S. Pascual } \\
\text { ( } 27 \text { marzo) }\end{array}$ & $\begin{array}{l}1 \text { (carnero) } \\
2 \text { (resto } \\
\text { carnes) }\end{array}$ \\
\hline 1418 & $\begin{array}{l}\text { Joan } \\
\text { Martínez, } \\
\text { carnicero. }\end{array}$ & Id. & Id. \\
\hline 1418 & $\begin{array}{l}\text { Pascual } \\
\text { Sanchez, } \\
\text { carnicero }\end{array}$ & Id. & Id. \\
\hline
\end{tabular}

CONDICIONES ESPECIFICAS AÑO 1418.

Deben tener dichas carnicerías bajo pena de 30 sueldos si no las mantienen abastecidas.

Excepto el jueves de vísperas, en que pueden tener una tabla de carnero y otra del resto de carnes sin pena alguna.

Deben tener 150 cabezas de carneros por tabla en la huerta y las ovejas, cabrónes y corderos que sean necesarios para las otras tablas de la huerta.

En la fiesta de carnavales deberán tener 1500 carneros para el próximo año.

Si el ganado de los carniceros hace daño en la huerta deberán pagar una multa de 10 sueldos. 


\begin{tabular}{|c|c|c|c|}
\hline AÑOYFECHA ARRENDAM. & ABASTEC. & DURACIÓN. & BANCOS. \\
\hline $\begin{array}{l}1421 \\
\text { (abril, 6) }\end{array}$ & $\begin{array}{l}\text { Bertomeu } \\
\text { Latorre } \\
\text { Lleona, } \\
\text { carnicero. }\end{array}$ & $\begin{array}{l}\text { Desde el } \\
1 \text { de mayo } \\
\text { a carnestol. }\end{array}$ & $\begin{array}{l}2 \text { (carnero) } \\
2 \text { (resto } \\
\text { carnes) }\end{array}$ \\
\hline 1421 & $\begin{array}{l}\text { Alfonso } \\
\text { Sanchez, } \\
\text { carnicero. }\end{array}$ & & Id. \\
\hline 1421 & $\begin{array}{l}\text { Joan Pinar, } \\
\text { vec. de } \\
\text { Alcaudete }\end{array}$ & Id. & Id. \\
\hline
\end{tabular}

CONDICIONES ESPECIFICAS ARRENDAMIENTO AÑO 1421.

Entre semana deben tener, cada carnicero, dos tablas de carneros y dos del resto de carnes, de sol a sol. Los domingos y fiestas "de tenir" deben tener tres tablas de carnero y una del resto de carnes de sol a sol, excepto el jueves de vísperas que deben tener una tabla de carnero. También se fijaba el precio de venta de la carne y el valor de la sisa. Se fijaba una multa de 30 sueldos a los arrendatarios ante cualquier incumplimiento de las condiciones fijadas. Se les permitía llevar 500 cabezas de ganado por tabla, en las partidas asignadas y que la mitad de las cabezas, correspondan a ovejas. Cumplido el mes de agosto los carniceros podían sacar de la villa las ovejas que no habían sido vendidas, si el consell no las requería. Si el ganado realizaba algún daño en la huerta los carniceros debian pagar las mulas pertinentes.

\begin{tabular}{|c|c|c|}
\hline AÑOY FECHA ARRENDAM. & DURACIÓN & BANCOS. \\
\hline $\begin{array}{l}1433 \\
\text { (septiembre, } \\
20)\end{array}$ & $\begin{array}{l}\text { Joan } \\
\text { Figuerola. }\end{array}$ & $\begin{array}{l}2 \text { (1 de carnero } \\
\text { y otra de } \\
\text { cabrón) }\end{array}$ \\
\hline 1433 & $\begin{array}{l}\text { Ferrando } \\
\text { Martínez. }\end{array}$ & $\begin{array}{l}2 \text { (1 de carnero } \\
\text { y otra de } \\
\text { cabrón) }\end{array}$ \\
\hline 1433. & Gil García & $\begin{array}{l}3 \text { (1 de } \\
\text { carnero, } \\
1 \text { de cabrón y } \\
1 \text { de cerdo). }\end{array}$ \\
\hline
\end{tabular}

CONDICIONES ESPECIFICAS ARRENDAMIENTO AÑO 1433.

No aparece fijada la duración del contrato. Joan Figuerola y Ferrando Martínez deben alternarse en la venta de carnero y cabrón. La multa por incumplimiento de alguna condición se fija en 60 sueldos. No aparecen fijados los precios de la carne ni su gravamen. 


$\begin{array}{llll}\text { ANOOY FECHA ARRENDAM. } & \text { ABASTEC. } & \text { DURACIÓN. } & \text { BANCOS. } \\ 1440 & \text { Manuel } & \text { Hasta } & \text { Las } \\ \text { (septiembre } & \text { Alvarez, } & \text { carnestoltes, } & \text { carnicerías } \\ 30) . & \text { ciudadano. } & \begin{array}{l}\text { y durante } \\ \text { un año más }\end{array} & \text { de la plaza. }\end{array}$

\section{CONDICIONES ESPECIFICAS ARRENDAMIENTO AÑO 1440.}

El contrato se inicia cuando "...los carnicers que a present tallen les carns qui tenen en la orta auran acabar de tallar aquelles..."

Solo podía entrar ganado en la huerta el arrendatario, al resto de propietarios se les vedaba el acceso. El ganado del arrendatario quedaba protegido frente a las posibles infracciones que cometiese en la huerta con una multa menor, que el resto del ganado, y con una fuerte multa a los dueños de heredades que sin motivo embargasen o matasen reses de dicho arrendatario.

El arrendatario tenía el monopolio de venta de carne, excepto los labradores que quisiesen sacrificar sus bueyes o vacas y la carne salvajina.

Cualquiera podía vender la carne de cabrito, al por menor, pagando la sisa correspondiente.

Al arrendatario se le permitía tener en la huerta 3500 cabezas de ganado, entre carneros, ovejas o cabrónes. Si al finalizar el contrato el arrendatario tenía todavía en su poder de 1500 a 2000 cabezas se le permitía venderlas en la carnicería, salvo que la renovación del contrato se conceda a otro arrendatario, en cuya caso podía sacar las reses sobrantes de la ciudad.

El arrendatario estaba obligado a mantener abastecidas las carnicerías.

$\begin{array}{llll}\text { AÑOYFECHA ARRENDAM. } & \text { ABASTEC. } & \text { DURACIÓN. } & \text { BANCOS. } \\ 1443 & \text { Manuel } & \text { Hasta } & \text { En las carnice- } \\ \text { (octubre, } & \text { Alvarez } & \text { pascua } & \text { rías de la ciu- } \\ 29) & \text { y Gómez } & \text { quincua } & \text { dad 2 (carnero) } \\ & \text { Daroca } & \text { gésima } & 1 \text { (carnes } \\ & & \text { menudas) } \\ & & \text { En el "ravalet" } \\ & & 1 \text { tabla } \\ & & \text { (carnero). }\end{array}$

CONDICIONES ESPECIFICAS ARRENDAMIENTO AÑO 1443.

El contrato abarcaba las carnicerías de la ciudad y del arrabal.

Durante los carnavales los aseguradores podían tener abastecida la ciudad de corderos, a precio de 10 dineros, con tres libras de sisa, salvo que alguien se ofrezca a venderlo a 9 dineros.

Los domingos y días festivos tenían que tener abastecidas en la ciudad 3 tablas de carnero y 1 de carnes menudas, aparte de la tabla del ravalet.

Los carniceros de los aseguradores debían desollar los cabritos, bueyes, vacas y salvaines que lleven los vecinos, a seis sueldos la cabeza. 
Al arrendatario se le permitía tener en la huerta hasta 2000 cabezas de carnero.

Los arrendatarios estaban obligados a mantener abastecidas las carnicerías.

$\begin{array}{llll}\text { AÑOYFECHA ARRENDAM. } & \text { ABASTEC. } & \text { DURACIÓN. } & \text { BANCOS. } \\ 1445 & \text { Daniel } & \text { Hasta } & 2 \text { (carnero), } \\ \text { (marzo, } & \text { Quexans, } & \text { carnestoltes } & 2 \text { (resto } \\ 15) & \text { mercader, } & & \text { carnes) } \\ \text { Joan } & & \text { y en el } \\ & \text { Martínez, } & \text { ravalet 1 } \\ \text { carnicero, } & \\ \text { J Manuel } & \\ & \text { Alvarez } & \\ & \text { y Gil García } & \end{array}$

CONDICIONES ESPECIFICAS AÑO 1445.

Deben tener abastecidas las tablas bajo el control del Justicia criminal y los jurados. El domingo y días festivos deben tener tres mesas de carnero, 1 con el resto de carnes y la del ravalet. El consell se reservaba una tabla para su gestión. Los arrendatarios debian desollar todos los bueyes que los labradores lleven a las carnicerías. No podían comprar el ganado que se vaya a sacrificar en la tabla del consell.

AÑOY FECHA ARRENDAM. ABASTEC. DURACIÓN. CABEZAS BANCOS.

$\begin{array}{lllll}\text { 1446, } & \text { Gómez } & \text { Desde abril } & 1500 & \text { Carnicerías } \\ \text { abril, } & \text { Daroca, } & \text { a } & \text { carneros } & \text { de la } \\ \text { 13. } & \text { Daniel } & \text { Carnavales. } & & \text { ciudad. } \\ & \text { Quexans, } & & \\ & \text { Joan } & & \\ & \text { Martínez. } & & \end{array}$

CONDICIONES ESPECIFICAS AÑO 1446.

El consell se reserva una tabla.

AÑO Y FECHA ARRENDAM. ABASTEC. DURACIÓN. CABEZAS. BANCOS.

$\begin{array}{lllll}\text { 1447, } & \text { Manuel } & \text { Desde abril } & 3700 & \text { Carnicerías } \\ \text { abril, } 11 & \text { Alvarez, } & \text { a } & \text { carneros } & \text { de la } \\ & \text { Joan } & \text { Carnavales. } & & \text { ciudad. } \\ & \text { Sanchez, } & & \\ & \text { carnicero. } & & \end{array}$

CONDICIONES ESPECIFICAS AÑO 1447.

Manuel Alvarez se compromete a sacrificar 1500 carneros que tiene en la huerta del término a 11 sueldos por libra de carne, y otros 1500 carneros procedentes del exterior a 12 sueldos. El consell acepta la oferta presentada por Joan Sánchez de 700 carneros. También autoriza el sacrificio y venta de carneros a 10 sueldos en la ciu- 
dad y ofrece para ello las tablas necesarias para quien acepte este precio. Para evitar fraudes se prohíbe que se compre al por mayor el ganado, a aquellos que quieran vender carne a 10 libras. El consel/ también autoriza la venta libre de carneros en las carnicerías de la ciudad a 12 dineros la libra de carne, desde abril hasta los próximos carnavales.

$\begin{array}{llll}\text { AÑOYFECHA ARRENDAM. } & \text { ABASTEC. } & \text { DURACIÓN. } & \text { BANCOS. } \\ 1451 & \text { Nicolau } & \text { Hasta } & \text { En las } \\ \text { (abril, 15) } & \text { Canals, } & \text { carnestoltes } & \text { carnicerías } \\ & \text { Daniel } & & \text { de la ciudad: } \\ & \text { Quexans, } & & 2 \text { (carnero) } \\ & \text { Diego } & & 2 \text { (resto } \\ & \text { Benavides, } & \text { carnes) } \\ \text { ciudadanos } & \text { En el "ravalet" } \\ & & 1 \text { tabla } \\ & & \text { (carnero } \\ & & \text { y cabrón, } \\ & & \text { oveja o } \\ & & \text { cordero). }\end{array}$

CONDICIONES ESPECIFICAS ARRENDAMIENTO AÑO 1451.

El contrato abarcaba las carnicerías de la ciudad y del arrabal.

El municipio se reservaba una carnicería abierta todo el año, para los que quieran "tallar molto" a un precio inferior para provisión de la ciudad. Los arrendatarios no podían comprar el ganado que los particulares llevasen a la carnicería del municipio.

Los arrendatarios estaban obligados a mantener abastecidas las carnicerías de sol a sol, con cuatro tablas, dos de carnero y dos con el resto de carnes, excepto buey y venado. Los domingos y días festivos debían tener tres tablas de carnero. La tabla del "ravalet" debía tener dos tipos de carne, de carnero y cabrón, cordero o oveja. Se prohibía a los arrendatarios "escorchar cabrits e lexar la taula".

Se prohibía a los guardias de la huerta excederse en su persecución, sobre el ganado que los carniceros tenían licencia para introducir en la huerta.

El arrendamiento solo tenía validez en época de paz.

$\begin{array}{llll}\text { ANO Y FECHA ARRENDAM. } & \text { ABASTEC. } & \text { DURACIÓN. } & \text { BANCOS. } \\ 1455, & \text { Diego } & \text { Hasta } & 3 \text { (carnero), } \\ \text { sin fecha } & \text { Bonavida } & \text { carnavales } & \text { (carnes } \\ & & & 2 \text { menudas) } \\ & & \text { Arrabal: } \\ & & 1 \text { (carnero) } \\ & & 1 \text { (carnes } \\ & & \text { menudas) }\end{array}$

CONDICIONES ESPECIFICAS AÑO 1455.

El arrendamiento se inicia después de que hayan sido sacrificados todos los car- 
neros inventariados que pastan en la huerta, cuyo precio de venta es 10 dineros la libra de carne.

El arrendatario se obliga a sacrificar los carneros que quedan en la huerta a 10 dineros. Tras esto se convierte en arrendatario con las condiciones y precios pactados.

El arrendatario se compromete a tener continuamente pobladas las tablas de carne.

Se prohíbe a los carniceros abandonar las tablas para scorchar cabritos, como es práctica frecuente que perjudica a los siseros.

Solo pueden sacrificar bueyes, vacas, cerdos, salvajinos y scorchar cabritos los carniceros del asegurador. Se fijan los precios: buey 6 sueldos y vaca 4 sueldos 6 dineros.

El arrendatario solo podía llevar por la huerta los carneros para abasto de las carnicerías, con un máximo de 1500 cabezas.

Las autoridades aseguran al arrendatario que los guardianes de la huerta no se excederán en el control del ganado que tiene pastando en la huerta.

El arrendatario se compromete a tener abastecidas a diario las carnicerias de sol a sol.

$\begin{array}{llll}\text { AÑOYFECHA ARRENDAM. } & \text { ABASTEC. } & \text { DURACIÓN. } & \text { BANCOS. } \\ \text { 1456, } & ? & \text { Junio a } & 2 \text { (carnero), } \\ \text { junio, } 5 & \text { Vilafranca, } & \text { Carnavales. } & 2 \text { (carnes } \\ & \text { Manuel } & & \text { menudas), } \\ & \text { Alvarez, } & & \text { "ravalet" } \\ & \text { Pere Mari. } & 1 \text { (carnero), } \\ & & 1 \text { (carnes } \\ & & \text { menudas). }\end{array}$

\section{CONDICIONES ESPECIFICAS AÑO 1456.}

Los arrendatarios se comprometen a tener pobladas continuamente las carnicerias.

Se prohibe a los carniceros abandonar las tablas para scorchar cabritos, como es práctica frecuente que perjudica a los siseros.

Solo pueden sacrificar bueyes, vacas, cerdos, salvajinos y scorchar cabritos los carniceros del asegurador. Se fijan los precios: buey 6 sueldos y vaca 4 sueldos 6 dineros.

El arrendatario solo podía llevar por la huerta los carneros para abasto de las carnicerías, con un máximo de 1500 cabezas y 600 de carnes menudas.

Durante el tiempo del arrendamiento se prohibe pastar ganado en la huerta que no sea para abastecer las carnicerías.

Se fijan los requisitos, pactados entre los jurados y los arrendatarios, sobre la entrada del ganado en la huerta.

Las autoridades aseguran al arrendatario que los guardianes de la huerta no se excederán en el control del ganado que tiene pastando en la huerta.

El arrendatario se compromete a tener abastecidas a diario las carnicerías de sol a sol.

El consell se reserva una tabla para vender carne a un dinero menos de precio. 
AÑO Y FECHA ARRENDAM.

1458 ,

mayo, 27
ABASTEC.

Manuel

Alvarez

Joan,

Martínez

y Gómez

Daroca.
DURACIÓN.

Mayo a

Carnavales.

2 (carnero),

2 (carnes

menudas)

"ravalet"

1 (carnero)

\section{CONDICIONES ESPECIFICAS AÑO 1458.}

Se prohíbe a los carniceros abandonar las tablas para scorchar cabritos, como es práctica frecuente que perjudica a los siseros.

Solo pueden sacrificar bueyes, vacas, cerdos, salvajinos y scorchar cabritos los carniceros del asegurador. Se fijan los precios: buey 6 sueldos y vaca 4 sueldos 6 dineros.

Los arrendatarios solo podian llevar por la huerta los carneros para abasto de las carnicerías, con un máximo de 1500 cabezas y 600 de carnes menudas.

Durante el tiempo del arrendamiento se prohíbe pastar ganado en la huerta que no sea para abastecer las carnicerías.

Se fijan los requisitos, pactados entre los jurados y los arrendatarios, sobre la entrada del ganado en la huerta.

Las autoridades aseguran al arrendatario que los guardianes de la huerta no se excederán en el control del ganado que tiene pastando en la huerta.

$\mathrm{El}$ arrendatario se compromete a tener abastecidas a diario las carnicerías de sol a sol.

Alfonso Vilafranca, que tiene arrendada una tabla en la ciudad, ha pactado con los jurados la venta de 2000 carneros a un dinero menos que el precio oficial fijado (vid. tabla precios) y que afecta al resto de arrendatarios.

FUENTE: A.M.O. Contestador, n. 16, f. 66v. n. 0 17, f. 57 r-v.n. 919 , f. 64 r-v. n. .21 , f. 80 r. n. .24 , ff. $96 r-98$; n. .25 , f. 86 r-v; n. .25 , f. 23 r-v; n. .27 , ff. $41 r-42 r$; n. .27 , ff. $16 v-$

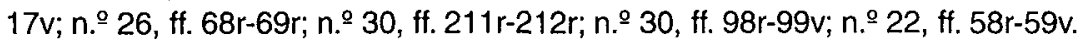

Desconocemos el número de carnicerías existentes en la huerta, alquerías y lugares del término de la villa. La mención en 1417 a quinientas cabezas por carnicería en la huerta, supone la existencia de una tabla en cada lugar de la huerta(38). En octubre de 1421 cuando Miguel Tortosa, vecino de la villa y carnicero del lugar de Catral, llevaba ciento once carneros con destino a la carnicería de dicho lugar y pasó por la población de Petrer, el alcaide de la aljama le obligo a pagar nueve sueldos en concepto de derecho de quema(39), por lo que dicho carnicero protestó ante el justicia criminal y jurados sobre dicho cobro, que así se lo hicieron saber al alcaide preterense, al que le exigieron la devolución del cobro de lo tomado, por considerarlo injusto(40).

Los abastecedores no pertenecian a familias destacadas de la oligarquía, lo que no implica la participación indirecta de algún miembro del patriciado como inversor, algo que desgraciadamente no podemos saber. 
Respecto a la regulación del oficio creemos que en Orihuela, como en Murcia, responde más al concepto "ganadero-empresario" propuesto por María Garcia(41) que al de carnicero propiamente dicho. La prueba se encuentra en los contratos de arrendamiento. Por una parte no todos los arrendatarios son carniceros y, por otra, en algunos capítulos se especifica que los aseguradores deben obligar a sus carniceros - trabajadores asalariados - a realizar determinada actividad. Respecto a la organización entre los contratistas de la venta de carne, al menos hasta el año 1446 cada uno se hacia cargo de una o varias tablas, pero desde esta fecha aparece la mención a los aseguradores y sus "companyons" en alusión a una posible organización empresarial entre cada uno de los arrendatarios y un número indeterminado de posibles socios capitalistas. La cesión se realizaba entre los jurados y los arrendatarios y sus "companyons". 


\section{NOTAS}

(1) BARRIO BARRIO, J.A. El ejercicio del poder en un municipio medieval: Orihuela, 1308-1479. Alicante, 1993. Tesis doctoral en microficha.

(2) ESTAL, J.M. del, Conquista y anexión de las tierras de Alicante, Elche, Orihuela y Guardamar al Reino de Valencia por Jaime // de Aragón. Alicante, 1982, doc. n. ${ }^{\circ}$ 83. (1321, mayo, 1).pp. 130-131.

(3) HINOJOSA MONTALVO, J. BARRIO BARRIO, J.A. "Las Sisas en la Gobernación de Orihuela durante la Baja Edad Media." Anuario de Estudios Medievales, 22 (1992), pp. 535-579.

(4) En 1446 los jurados habían establecido contacto con dos grupos de socios para la gestión de las carnicerías. Ante la duda sobre la oferta a aceptar, la cuestión se delibero en sesión plenaria del consell, en la que finalmente se aprobaron los capítulos de cesión y el nombre de los arrendatarios. A(rchivo) M(unicipal) de O(rihuela). Contestador, n. .27 , f. 41 r-v. (1446, abril, 13).

(5) BARRIO BARRIO, J.A. El ejercicio del poder...

(6) MARÍN GARCÍA, M.A. "Las carnicerías y el abastecimiento de carne en Murcia (1450-1500)", Miscelánea Medieval Murciana, XIV (1987-1988), pp. 51-99.

(7) BARRIO BARRIO, J.A. "La ganadería oriolana en el siglo XV: la regulación de los pastos", Investigaciones Geográficas, 12 (1994), pp. 247-254.

(8) BONACHIA HERNANDO, J.A. "Abastecimiento urbano, mercado local y control municipal: La provisión y comercialización de la carne en Burgos ( siglo XV). Espacio, Tiempo y Forma, Serie III, H. . Medieval, V (1992), pp. 85-162.

(9) A.M.O. Contestador, n.․ 15, f. 206r. (1416, marzo, 29).

(10) En Murcia y Burgos el carnero era también el principal producto de consumo carnicero. MARÍN GARCÍA, M.A. "Las carnicerías y el abastecimiento de carne..." BONACHIA HERNANDO, J.A. "Abastecimiento urbano..." En Inglaterra la carne más consumida por los aristócratas era la bovina. DYER, $\mathrm{CH}$. Niveles de vida en la Baja Edad Media. Barcelona, 1991, p. 84.

(11) A.M.O. Contestador, n. 21 , f. 33 r-v. (1433, abril, 14).

(12) En Barcelona, a principios del siglo XIV había cinco mataderos que pertenecían al rey como monopolio real administrado por el baile. BATLLE, C. "Contribució a la història dels oficis de Barcelona: els carnissers del segle XIII", Quaderns d'estudis medievals, any II, n.o 5, vol. 1, sept. 1981, pp. 310-318. En la Seo de Urgell existía un matadero propiedad del Obispo. BATLLE, C. "Contribució a la història 
dels oficis a la Seu d'Urgell: els carnissers (1250-1350)", Urgellia, V, 1982, pp. 221-279. Desconocemos para Orihuela la existencia de mataderos.

(13) A.M.O. Contestador, n.. 21, f. 77r. (1433, septiembre, 8).

(14) DYER, CH. Niveles de vida...

(15) Ante esta queja el consell ordenó que se matase el buen ganado que había pastado en la huerta de la villa "...en tal forma que aja provesio e los sisers no perden per rao de la mala carn....'. A.M.O. Contestador, n. ${ }^{\circ} 16$, f. 10r. (1417, enero, 6).

(16) GUERRERO NAVARRETE, Y. Organización y gobierno de Burgos durante el reinado de Enrique IV de Castilla. 1453-1476. Madrid, 1986, p. 325.

(17) A.M.O. Contestador, n. .15 , f. 195v. (1416, marzo, 20).

(18) En este caso pagan los labradores que llevan sus bueyes a la carnicería seis dineros, por el "tallar".

(19) BARRIO BARRIO, J.A. "La ganadería oriolana en el siglo XV..." Por ej. en 1418 los jurados de la villa autorizaron a Latorre Leona a ir por la huerta con setecientos carneros, que quedaron obligados para ser sacrificados para provisión de la villa. A.M.O. Contestador, n.․ 17, f. 53r. (1418, febrero, 16).

(20) Ibidem.

(21) A.M.O. Contestador, n. ${ }^{-17}$, f. 96r. (1418, abril, 22).

(22) A.M.O. Contestador, n. 17, f. 113r. (1418, junio, 5).

(23) Ferrando Martínez y Pascual Sánchez, carniceros de Orihuela, acudieron en 1418 a la feria de Alpera a comprar carneros para venderlos en las carnicerías que tenían en la villa. A.M.O. Contestador, n. ${ }^{17}$, f. 127r. (1418, septiembre, 23).

(24) HARRIS, M. Bueno para comer. Enigmas de alimentación y cultura. Madrid, 1994, p. 19.

(25) A.M.O. Contestador, n.. 21, f. 50 r-v. (1432, mayo, 11).

(26) A.M.O. Contestador, n.. 21, f. 51r. (1432, mayo, 25).

(27) A.M.O. Contestador, n. .21 , f. 52r. (1432, junio, 3).

(28) A.M.O. Contestador, n. ${ }^{9} 25$, f. 22v. (1443, enero, 31).

(29) En la Carnicería Mayor de Valencia se arrendaban hasta un máximo de siete tablas, dejando una más vacía para la venta libre. GARCíA MARSILLA, J.V. La jerarquía de la mesa. Los sistemas alimentarios en la Valencia Bajomedieval. Valencia, 1993, p. 109. En Orihuela en 1421 el número de tablas arrendadas en la ciudad se elevó hasta doce.

(30) En Murcia la situación era similar, existía una Carnicería Mayor que disponía de varias tablas con diferentes tipos de carne y la Carnicería Nueva con dos tablas. MARÍN GARCÍA, M.A. "Las carnicerías y el abastecimiento de carne..."

(31) MARÍN GARCÍA, M.A. "Las carnicerías y el abastecimiento de carne..." pp. 7576.

(32) Ferrando Martínez, dos carnicerías. Alfons Sánchez, una de venta de carnero. Pascual Sánchez, dos carnicerías. Y Ferrando Martí que acababa de avecindarse el día anterior al arrendamiento, procedente de Cartagena dos carnicerías. Lo que es una muestra de la poca competencia que existía en la villa entre los car- 
niceros en las primeras décadas del siglo XV. A.M.O. Contestador, n. 16, f. $66 \mathrm{v}$. (1417, marzo, 30). En 1427 Ferrando Martínez regentaba una de las carnicerías, situada en la plaza de la villa, aunque debido a una ampliación que se había realizado en la plaza se le había ocupado la carnicería por lo que los jurados de acuerdo con el consell le concedieron una nueva carnicería en la misma plaza. A.M.O. Contestador, n. 20 , f. 57v. (1427, marzo, 29). Poco después, Ferrando Martínez vendia a los jurados de la villa, en nombre del consell, la carnicería que tenía en la plaza por precio de cuarenta florines de oro. A.M.O. Contestador, n.. 20, f. 84 r-v. (1427, septiembre, 27). En 1433 el justicia criminal y los jurados concedieron las carnicerías de la villa con el resultado siguiente: Ferrando Martínez, una carnicería de carnero y otra de cabrón, Joan Figuerola, una carnicería de carnero y otra de cabrón. Ferrando Martínez y Joan Figuerola, debían alternarse. Si uno tenía abierta la carnicería de carnero, el otro debía tener abierta la suya de cabrón, y al reves. Guillén García, una de carnero, otra de cabrón y otra de cerdo. A.M.O. Contestador, n. ${ }^{2} 21$, f. 80r. (1433, septiembre, 20). El número de carniceros existentes en Orihuela en las primeras décadas del siglo XV, contrasta por ejemplo con los más de treinta que existían en la Seo d'Urgell entre 1330 y 1349. BATLLE, C. "Contribució a la història dels oficis a la Seu d'Urgell..." pp. 222-224.

(33) Casi dos meses después de la concesión de las carnicerías, el consell recibió una oferta de Joan Martínez, carnicero que se ofreció a vender carne en las carnicerías de la villa a un dinero menos la libra del carnero que como la vendían los otros carniceros. El consell le ofreció la posibilidad de concederle las carnicerías que había recibido Fernando Martí, recién llegado de Cartagena, "...que li donen les taules que foren otorgades al de Cartagenia...". Si esta posibilidad no era valida, el consell le ofrecía la alternativa de plantear su propuesta en otra reunión para volver a estudiarla. A.M.O. Contestador, n. 16, f. 95r. (1417, mayo, 16). Finalmente Joan Martínez recibió la carnicería solicitada, en detrimento de Fernando Martí, recién llegado de Cartagena, que perdió la carnicería. A.M.O. Contestador, n.- 16, f. 136v. (1417, agosto, 21).

(34) En agosto de 1417 estaban enfrentados Ferrando Martínez y Pascual Sánchez contra Joan Martínez y Alfonso Sánchez, por la venta que estos dos últimos habian realizado a los primeros de carneros, cabrónes y ovejas. El consell ordenó en esta cuestión que el justicia criminal, los jurados y algunos "hòmens bons" viesen la cuestión entre los carniceros y que actuasen para que los cuatro carniceros "tallen axi com son obligats al consell". A.M.O. Contestador, n. 16 , f. 136v. (1417, agosto, 21).

(35) A.M.O. Contestador, n.. 19, f. 40r. (1421, enero, 31). En la reunión del consell de 22 de febrero, el consell dio poder al justicia criminal y los jurados, para que con algunos "hòmens bons" viesen los capítulos que había ofrecido el carnicero de Valencia y que decidiesen con aquel sobre la concesión de las carnicerías de la villa. A.M.O. Contestador, n. ${ }^{2} 19$, f. 48 r. (1421, febrero, 22$)$.

(36) BARRIO BARRIO, J.A. El ejercicio del poder...

(37) A.M.O. Contestador, n. 0 19, f. 64 r-v. (1421, abril, 6). Los tres asegurados fueron Bertomeu Latorre Lleona, Alfons Sánchez, carniceros, vecinos de la villa de Orihuela, y Joan Pinar, vecino de Alcaudete. 
(38) “...cinchcents cabeces per taula en la orta...". A.M.O. Contestador, n. 16, f. $66 \mathrm{v} .(1417$, marzo, 30).

(39) Sobre el tributo de La quema vid.. CANET APARISI, T. "Los orígenes medievales de un impuesto moderno: La Quema", Revista de Historia Moderna. Anales de la Universidad de Alicante, 3, Alicante, 1983, pp. 181-190.

(40) A.M.O. Contestador, n. 19, f. 137v. (1421, noviembre, 5).

(41) MARÍN GARCÍA, M.A. "Las carnicerías y el abastecimiento de carne..." p. 69. 